\title{
Inhibition of platelet release reaction by acetylsalicylic acid
}

\author{
R. M. ROWAN \\ M.B., M.R.C.P.
R. L. RENTON*
M.B., D.I.H.

\author{
G. A. McDonald \\ M.D., F.R.C.P., M.R.C.Path.
}

S. J. CORNE*

B.Pharm., Ph.D., F.P.S.

\author{
D. F. BRown \\ M.B., Ch.B. \\ Department of Haematology, Glasgow Royal Infirmary and \\ * Nicholas Research Institute, Slough, Bucks
}

\begin{abstract}
Summary
The inhibitory potency and duration of action of single doses of aspirin B.P., claradin (a low sodium effervescent preparation of acetylsalicylic acid) and aloxiprin (an aluminium co-polymer of acetylsalicylic acid) on platelet release reaction induced by adenosine diphosphate (ADP) were studied in seventeen volunteers. Aspirin B.P. and claradin at $300 \mathrm{mg}$ and $150 \mathrm{mg}$ inhibited release reaction in all subjects within $24 \mathrm{hr}$; $75 \mathrm{mg}$ was effective only in some subjects. Aloxiprin gave less marked response and a dose of $300 \mathrm{mg}$ was required to inhibit the effect in all volunteers. Where occurring, inhibition of release reaction persisted for three days after treatment with all preparations and restoration to normal occurred in most subjects by the sixth day.

A daily dose of $50 \mathrm{mg}$ claradin for 12-15 days in five volunteers produced complete inhibition of release reaction for most of the treatment period. Inhibition of release reaction took up to 3 days to occur. Normal aggregation returned within 3 days of discontinuing treatment in all subjects. A daily dose of $25 \mathrm{mg}$ claradin gave inconsistent results.

It is suggested that if a trial of acetylsalicylic acid be undertaken for the prevention of arterial thrombosis based on its ability to inhibit platelet release reaction then a daily dose of $50 \mathrm{mg}$ would be sufficient.
\end{abstract}

\section{Introduction}

During the past decade considerable research activity has centred on drugs which inhibit platelet function. Mustard and Packham (1970) have comprehensively reviewed all aspects of platelet adhesion and aggregation and their clinical implications. It has long been suggested that pharmacological agents which inhibit platelet adhesion and aggregation may

Correspondence: Dr R. M. Rowan, Department of Haematology, Royal Infirmary, Glasgow. be clinically useful in the prevention of thrombotic incidents (McDonald and Edgill, 1959; Breddin, 1968; Bygdeman and Wells, 1969; Renaud and Godu, 1970; Weiss, Danese and Valeti, 1970; Wood, 1972; Breddin, 1973). Inhibitors of platelet function, both naturally occurring substances and drugs, may be divided into three categories, namely (a), selective inhibitors of specific aggregating agents; (b), general inhibitors of primary aggregation; (c) specific inhibitors of secondary aggregation (Mills, 1972). This last group includes acetylsalicylic acid (ASA), a drug which appears promising as an effective and safe anti-aggregant (O'Brien, 1968a; Weiss, Aledort and Kochwa, 1968; Renaud and Godu, 1970; Stuart, 1970; Weiss et al., 1970).

Clearly, a therapeutic trial of salicylates is justified in individuals at risk from arterial thrombosis and it has even been suggested that such a trial be extended to all men over the age of 20 years and all women over the age of 40 years on a long term basis (Wood, 1972). Exceptions to this would be persons suffering from haemostatic defects, allergy to salicylates, and a previous history of bleeding from the gastrointestinal tract or other system.

It is the purpose of this paper to report studies designed to assess the potency and duration of inhibition of platelet release reaction produced by various pharmaceutical formulations of ASA over a spectrum of dosage levels in normal volunteers. Furthermore, since gastro-intestinal haemorrhage is a well recognized complication of prolonged salicylate ingestion, it becomes mandatory to define the minimum effective drug dosage (Andrássy et al., 1973).

\section{Subjects and methods}

For each of the studies, volunteers were obtained from two centres, Glasgow and Slough. All aspects 
of sampling and technique were carefully standardized between the two centres. Venous sampling was carried out at a fixed time of day for each individual. Using disposable plastic syringes, blood was obtained by clean venepuncture and mixed with $3.8 \%$ trisodium citrate in a ratio of $9 \mathrm{~V}$ of venous blood to $1 V$ citrate, the blood being taken either into siliconized glass bottles capped with parafilm or into plastic containers. An initial $18 \mathrm{ml}$ sample of blood was required for base-line studies, but thereafter $9 \mathrm{ml}$ were sufficient.

Platelet rich plasma (PRP) was prepared immediately by centrifugation at $150 \mathrm{~g}$ for $10 \mathrm{~min}$ at room temperature. Aliquots of PRP were placed in disposable polystyrene tubes and kept at room temperature $\left(17-22^{\circ} \mathrm{C}\right)$ until testing. All aggregation studies were completed within $1 \mathrm{hr}$ of venous sampling. PRP platelet counts were performed on the Coulter Thrombocounter C (Rowan, 1973) to ensure that the samples contained between 250,000 and 400,000 platelets $/ \mathrm{ml}$.

Platelet aggregation was measured by the turbidimetric method of Born (1962) and O'Brien (1962) using either a Bryston aggregometer (Glasgow) or an Eel Model 169 aggregometer (Slough). Both instruments measure changes in optical density of PRP at $37^{\circ} \mathrm{C}$ as platelets aggregate. Since different volumes of PRP were used in the two instruments, an arithmetical correction factor was applied to give comparable results. After pre-warming at $37^{\circ} \mathrm{C}$ for $2 \mathrm{~min}$, the PRP to be tested was added to the reaction cuvette of the aggregometer and there continuously agitated by a magnetic stirrer at $1100 \mathrm{rev} / \mathrm{min}$. Changes in optical density were recorded on a Servoscribe single channel recorder which had previously been adjusted to give a maximal optical density reading on the subject's PRP and a fullscale deflection $(1 \mathrm{mV})$ with the corresponding platelet poor plasma.

The sodium salt of ADP (Sigma) was dissolved in distilled water to a concentration of $1 \mathrm{mmol} / 1$. This stock solution was stored in aliquots at $-20^{\circ} \mathrm{C}$ and working solutions were prepared on the day of use by further dilution in barbitol-buffered saline at pH 7.35. In each volunteer, the minimum concentration of ADP which produced a secondary wave of platelet aggregation was taken as the base-line for all subsequent studies.

All volunteers selected demonstrated reproducible biphasic platelet aggregation in citrated PRP in response to exogenous ADP. There were 140 normal subjects who had previously been studied and the lowest concentration of ADP required to induce secondary platelet aggregation ranged from $0 \cdot 5-1 \cdot 8$ $\mu \mathrm{mol} / 1$, levels which were in broad agreement with those reported by Hardisty et al. (1970).

A check list of ASA-containing preparations and other platelet inhibiting drugs was prepared and circulated to all volunteers to ensure that medication which might interfere with the study would be avoided.

The aim of the first study was to monitor the duration of inhibition of secondary aggregation following single doses of ASA. Three different preparations were used, aspirin B.P., aloxiprin, which is an aluminium co-polymer of ASA, and claradin which is a low sodium effervescent preparation of ASA. Each drug was given in doses of 300 , 150 , and $75 \mathrm{mg}$. Seventeen healthy volunteers (eleven male and six female) of age range 18-45 years were studied initially. Each volunteer was subjected to nine cycles of investigation, drug and dose being randomly allocated. The previous medical history of all volunteers had been carefully scrutinized and present health status was assessed. No pregnant subject was accepted, nor was anyone with a history suggestive of allergy to ASA. Any person with a history of regular dyspepsia which might predispose to gastro-intestinal haemorrhage was excluded. Platelet aggregation studies were performed before each dose of ASA to confirm the existence of base-line release reaction and subsequently on the first, third and sixth days following drug ingestion. In some subjects it was necessary to take further samples before full restoration of plate let function became evident.

The second study involved five healthy volunteer who were given $50 \mathrm{mg}$ claradin daily for up to 14 days. The same stringent criteria were applied in the selection of volunteers for this part of the study. Aggregation studies were performed immediately before therapy started on day 1 to establish base-line values. Subsequently, specimens were examined daily until several days after inhibition of biphasic response occurred. Thereafter specimens were examined at intervals until dosage ceased. At the end of the test period, when treatment was discontinued, aggregation studies were performed daily until a return to base-line biphasic response occurred.

A third study was carried out on four volunteers using $25 \mathrm{mg}$ claradin daily. Two subjects took this preparation after an overnight fast; the remainder following a light breakfast. Aggregation studies were performed daily until inhibition of platelet release reaction was achieved or to a maximum of 6 days.

\section{Results}

\section{First study}

The results are summarized in Table 1 in terms of the number of times secondary aggregation did not occur on the first, third and sixth days after ASA ingestion for each preparation at each dose level. In the Glasgow volunteers no significant difference 
TABLE 1. Number of times secondary aggregations not achieved on each ASA preparation after 1, 3, and 6 days (i.e. the number of times the effect of ASA was noted)

\begin{tabular}{lllllllllllll}
\hline \multirow{2}{*}{ Centre } & Dose & \multicolumn{3}{c}{$75 \mathrm{mg}$} & \multicolumn{3}{c}{$150 \mathrm{mg}$} & \multicolumn{3}{c}{$300 \mathrm{mg}$} \\
& Treatment & Days & 1 & 3 & 6 & 1 & 3 & 6 & 1 & 3 & 6 \\
\hline Glasgow & Aspirin B.P. & & 9 & 7 & 4 & 9 & 9 & 6 & 9 & 9 & 7 \\
9 Volunteers & Claradin & & 9 & 8 & 1 & 9 & 9 & 6 & 9 & 9 & 3 \\
& Aloxiprin & & 8 & 5 & 1 & 9 & 9 & 5 & 9 & 9 & 4 \\
Slough & Aspirin B.P. & & 5 & 3 & 0 & 8 & 6 & 2 & 8 & 6 & 0 \\
8 Volunteers & Claradin & & 7 & 5 & 2 & 8 & 5 & 1 & 8 & 5 & 2 \\
& Aloxiprin & & 2 & 6 & 0 & 5 & 3 & 2 & 8 & 4 & 1 \\
\hline
\end{tabular}

was noted between subjects or treatments. The responses, however, at $75 \mathrm{mg}$ were significantly less than those of $150 \mathrm{mg}$ and $300 \mathrm{mg}(P<0.05)$; there was evidence of a levelling of dose response at $150 \mathrm{mg}$.

In the Slough volunteers the results were more variable and large differences were noted between the subjects and treatments. The treatment differences arose mainly from the reduced response to aloxiprin. As in the Glasgow results, the responses after $75 \mathrm{mg}$ were significantly less $(P<0.05)$ than at the other two doses and there was an indication of levelling in the dose response curve at $150 \mathrm{mg}$. All subjects taking aspirin B.P. and claradin at the $300 \mathrm{mg}$ and $150 \mathrm{mg}$ dose levels demonstrated inhibition of secondary aggregation after $24 \mathrm{hr}$. The duration of inhibition differed in individuals but this was presumed to be due to variation in platelet turnover. Some subjects demonstrated an effect for 10 days. Aspirin B.P. produced inhibition of platelet aggregation in excess of $72 \mathrm{hr}$ in sixteen of seventeen subjects studied and claradin in fifteen of seventeen subjects. With aloxiprin, while all volunteers demonstrated inhibition of secondary aggregation at $300 \mathrm{mg}$, persistence of biphasic reaction occurred in two subjects at $150 \mathrm{mg}$ and in three subjects at $75 \mathrm{mg}$. All Glasgow volunteers, if showing inhibition, did so $24 \mathrm{hr}$ after commencing treatment. The situation differed with the Slough volunteers in that on seven occasions (aloxiprin $75 \mathrm{mg} \times 5$, aloxiprin $150 \mathrm{mg} \times$ 1 , claradin $75 \mathrm{mg} \times 1$ ) secondary aggregation persisted at $24 \mathrm{hr}$ but was inhibited at $72 \mathrm{hr}$ (Fig. 1).

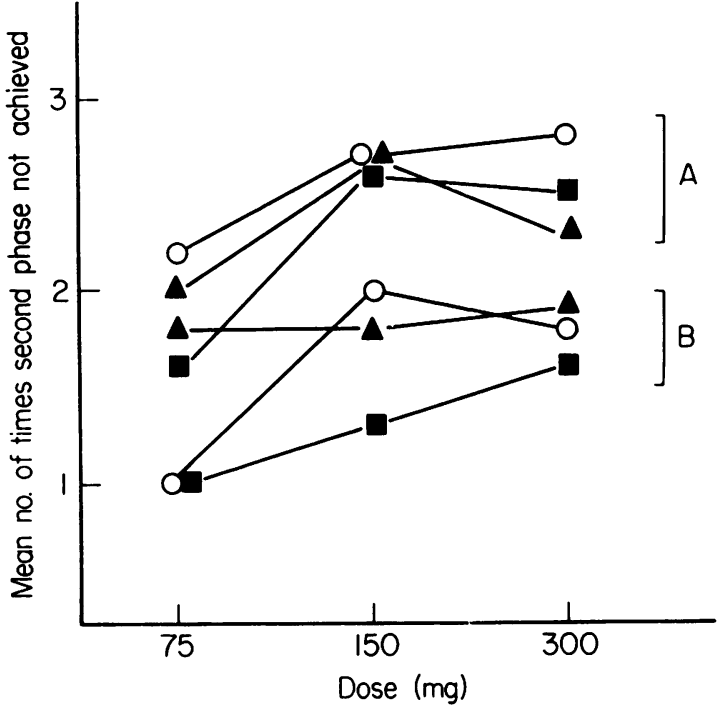

FIG. 1. Inhibition of secondary platelet aggregation by aspirin B.P., $\bigcirc-O$; claradin, $\Lambda-\Lambda$; and aloxiprin, - - A, Glasgow and B, Slough volunteers.

\section{Second study}

Using claradin in a dose of $50 \mathrm{mg}$ daily, all subjects show inhibition of secondary aggregation but induction occurred at different rates, Slough volunteers taking longer than Glasgow volunteers (Table 2).

TABLE 2. Duration of inhibition of secondary platelet aggregation produced by claradin $50 \mathrm{mg} / \mathrm{day}$

\begin{tabular}{|c|c|c|c|c|c|c|c|c|c|c|c|c|c|c|c|c|c|c|c|}
\hline \multirow[b]{2}{*}{ Centre } & \multirow[b]{2}{*}{ Volunteer no. } & \multicolumn{18}{|c|}{ Day } \\
\hline & & 1 & 2 & 3 & 4 & 5 & 6 & 7 & 8 & 9 & 10 & 11 & 12 & 13 & 14 & 15 & 16 & 17 & 18 \\
\hline \multirow[t]{3}{*}{ Slough } & 1 & + & + & + & - & - & - & - & - & & - & & - & & - & - & + & + & \\
\hline & 2 & + & + & - & - & - & - & - & - & & - & & - & ( ) & - & + & + & & \\
\hline & 3 & + & + & - & - & - & - & - & & - & & - & ( ) & - & - & + & + & & \\
\hline \multirow[t]{2}{*}{ Glasgow } & 4 & + & - & - & - & - & & & - & - & & & - & & $(-)$ & - & - & + & \\
\hline & 5 & + & - & - & - & - & & & - & - & & & - & & $(-)$ & - & - & - & + \\
\hline
\end{tabular}

+ , Secondary aggregation occurred; - , secondary aggregation inhibited; $($ ), indicates that this was the last day of dosage. 


\section{Third study}

The four volunteers taking claradin $25 \mathrm{mg}$ daily failed to show consistent results whether ingestion occurred in the fasting or the non-fasting state. This level of dosage was considered unsatisfactory and not pursued.

\section{Discussion}

Evidence continues to accumulate implicating the platelet in the initiation of arterial thrombus formation. Platelets rapidly adhere to exposed collagen in the arterial tree and subsequently undergo release action (Mustard, Rowsell and Murphy, 1966). The ADP liberated causes other platelets to aggregate which in turn sets up a chain reaction. Thus, drugs which interfere with this process may well prevent thrombus formation.

Many common drugs impair platelet aggregation in vitro (Mustard et al., 1966; Evans et al., 1967; Mills and Roberts, 1967; Weiss et al., 1968) but ASA has been the most widely studied. During these studies, a wide range of doses has been used varying from 150 to $3600 \mathrm{mg}$ daily (O'Brien, 1968a, b; Weiss et al., 1968; Zucker and Peterson, 1968; Stuart, 1970; Hirsch et al., 1973). However, above $150 \mathrm{mg}$, the degree of inhibition of platelet aggregation does not increase (Bjornson and Eika, 1973).

The mechanism whereby ASA affects platelet function is incompletely defined. The observation that platelets can remain abnormal for several days after the ingestion of a single dose of ASA suggests that platelets are permanently affected by the drug and that restoration to normal probably represents the appearance of a new platelet population. Rosenberg et al. (1971) have demonstrated that platelets are acetylated by ASA probably via a mechanism involving the membrane protein. This will affect the physico-chemical properties of the platelet membrane protein which could account for the inhibition of secondary aggregation. An alternative or additional explanation is afforded by the work of Vargaftig and Zirinis (1973) who found that ASA and other anti-inflammatory drugs inhibit the production of a cyclic endoperoxide intermediate formed during the biosynthesis of prostaglandins from arachidonic acid in human and rabbit platelets. They suggest that this intermediate is responsible for platelet aggregation induced by collagen and that ADP released during the process plays an essential role.

ASA is absorbed from all parts of the gastrointestinal tract including the stomach. While initial absorption of ASA takes place across the gastric mucosa, the major site of absorption appears to be the proximal portion of the small intestine (Levy, 1961). This is the result of the interaction of a num- ber of factors including the pH of the stomach and small intestine, the rate of stomach emptying, theo rate of dissolution and the degree in dissociation of $\mathrm{c}_{c}$ the ASA molecule. The pharmaceutical formulation: can influence all of these and is therefore of impors tance.

In the first study, aspirin B.P. and claradin at the음 300 and $150 \mathrm{mg}$ dose level produced uniform in $-\frac{\overline{5}}{\frac{1}{6}}$ hibition of secondary platelet aggregation. The over $-\frac{\Phi}{\Omega}$ all performance with these preparations at the $75 \mathrm{mgon}$ level was good but not completely predictable. Aloxiprin, on the other hand, gave less satisfactory. results, particularly at doses of 75 and $150 \mathrm{mg}$. This $\vec{\omega}$ difference is presumably related to the variation in $\omega$ pharmaceutical formulation. The rates of dissolution of aspirin B.P. and claradin are much greater than 3 . that of aloxiprin and consequently the rates of absorption of the former preparations are more rapid, resulting in earlier and higher peak levels. A study comparing serum salicylate concentrations after single doses of claradin and aspirin B.P. showed thato the former resulted in a peak level 10-20 min after ingestion whereas the latter did not show a definite ${ }_{T}$ maximum during the $60-\mathrm{min}$ period of studyo (Cummings, Martin and Renton, 1971). Furthermore, the serum salicylate level achieved with claradin was substantially higher than that achievgd $\overrightarrow{-}$ by aspirin B.P. at all times. For this reason clara was preferred to aspirin B.P. during the subseque part of the present investigation. The slower absor -O tion of aspirin B.P. implies longer contact with gastro-intestinal mucosa and could therefore increase the risk of side effects.

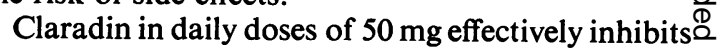
platelet release reaction in healthy volunteers. There $\overrightarrow{\vec{\sigma}}$ would, however, appear to be a population difference 3 at this dose level. Glasgow volunteers invariably? showed inhibition within $24 \mathrm{hr}$ of starting treatment whereas volunteers from Slough required 48-72 hro for protection. The reason for this is not apparent. However, once inhibition occurs with $50 \mathrm{mg}$ claradin $\frac{0}{3}$ daily the effect persists until some days after discontinuing treatment.

A daily dose of $25 \mathrm{mg}$ claradin produced an unpredictable response in terms of platelet aggrega-음 tion and no difference was noted in relation to food $>$ ingestion.

Evidence is now accumulating to support a N therapeutic trial of ASA for the prevention of arterial thrombosis. If platelet aggregation studies ${ }_{N}$ accurately reflect in vivo platelet release phenomena, $\omega$ the results of the present study suggest that a daily dose of $50 \mathrm{mg}$ ASA would be suitable for such a ${ }^{\circ}$ trial. Furthermore, it is of interest to note that these studies have revealed that inhibition of platelet ${ }^{\text {? }}$ release reaction may be the most potent action of $\frac{0}{T}$ ASA in man. 


\section{Acknowledgments}

We wish to thank Dr I. W. Jamieson for his invaluable help throughout the study. We are also indebted to Miss C. Fraser, Miss J. Reid, Mrs P. McPherson, Mrs S. Gibson, Miss J. E. Jemmett and Mr C. D. Johnston for technical assistance. We also thank Mrs J. E. Marshall for administrative co-ordination and Mr J. Bigham for statistical advice. Finally, we acknowledge our gratitude to the colleagues in both centres who so readily volunteered to partake in these studies.

\section{References}

Andrássy, K., Malluche, B., Comberg, M., Bornefield, H., Ritz, E. \& Bucholtz, L. (1973) Prevention of postoperative A.V. Cimino fistula clotting with acetyl salicylic acid: a prospective double blind study. IVth International Congress on Thrombosis and Haemostasis, Vienna. Abstracts, 135.

Buornson, J. \& EIKA, C. (1973) Platelet function after intoxication with acetyl salicylic acid. IVth International Congress on Thrombosis and Haemostasis, Vienna. Abstracts, 363.

BoRN, G.V.R. (1962) Aggregation of blood platelets by adenosine diphosphate and its reversal. Nature, London, $194,927$.

BREDDIN, K. (1968) Experimental and clinical investigations on the adhesion and aggregation of human platelets. Proceedings of the Society for Experimental Biology and Medicine, 3, 14.

BREDDIN, K. (1973) Prophylaxis of arterial and venous thrombosis by inhibition of platelet aggregation. IVth International Congress on Thrombosis and Haemostasis, Vienna. Abstracts, 11.

Bygdeman, S. \& Wells, R.J. (1969) Studies of platelet adhesiveness, blood viscosity and the microcirculation in patients with thrombotic disease. Journal of Atherosclerosis Research, 10, 33.

Cummings, A.J., Martin, B.K. \& Renton, R.L. (1971) Serum salicylate concentrations obtained after single doses of low sodium effervescent aspirin and aspirin B.P. tablets. Internal Report: Nicholas Research Institute.

Evans, G., Nishizawa, E.E., Packham, M. \& MUStard, J.F. (1967) Effects of acetyl salicylic acid on platelet function. Blood, 30, 550.

HaRdisty, R.M., HutTon, R.A., MONTGOMERY, D., Rickard, S. \& Trebilcock, H. (1970) Secondary platelet aggregation: A quantitative study. British Journal of Haematology, 19, 307.

Hirsch, J., STReet, D., CADE, J.F. \& AMy, H. (1973) Relation between bleeding time and platelet connective tissue reaction after aspirin. Blood, 41, 369.

LEVY, G. (1961) Comparison in dissolution and absorption rates of different commercial aspirin tablets. Journal of Pharmaceutical Sciences, 50, 388.
MiLls, D.C.B. (1972) Drugs that affect platelet behaviour. Clinics in Haematology, 1, 295.

MiLls, D.C.B. \& RobeRTS, G.C.K. (1967) Membrane active drugs and the aggregation of human blood platelets. Nature. London, 213, 35.

Mustard, J.F. \& PaCkham, M.A. (1970) Factors influencing platelet functions: adhesion, release and aggregation. Pharmacological Review, 22, 97.

Mustard, J.F., Rowsell, H.C. \& Murphy, E.R. (1966) Platelet economy (survival and turnover). British Journal of Haematology, 12, 1.

McDonald, L. \& Edgill, M. (1959) Coagulability of the blood during various phases of ischaemic heart disease. Lancet, i, 1115.

O'BRIEN, J.R. (1962) Platelet aggregation. II. Some results from a new method of study. Journal of Clinical Pathology, $15,452$.

O'BRIEN, J.R. (1968a) Effects of salicylates on human platelets. Lancet, i, 779.

O'BRIEN, J.R. (1968b) Aspirin and platelet aggregation. Lancet, i, 204.

Renaud, S. \& Godu, J. (1970) Thrombosis prevention by acetyl salicylic acid in hyperlipaemic rats. Canadian Medical Association Journal, 103, 1037.

Rosenberg, R.J., Gimber-Phillips, P.E., Goblewski, G.E., Davidson, C., Phillips, D.K., Goralnick, S.J. \& Cahill, E.D. (1971) Acetyl salicylic acid: Inhibition of platelet aggregation in the rabbit. Journal of Pharmacology and Experimental Therapeutics, 179, 410.

Rowan, R.M. (1973) Evaluation of the Thrombocounter C. Coulter Counter User's Conference (Coulter Internal Publication) London.

Stuart, R.K. (1970) Platelet function studies in human beings receiving $300 \mathrm{mg}$ of aspirin per day. Journal of Laboratory and Clinical Medicine, 75, 463.

VARGaftIG, B.V. \& Zirinis, P. (1973) Platelet aggregation induced by arachidonic acid is accompanied by release of potential inflammatory mediative district from $\mathrm{PGE}_{2}$ and $\mathrm{PGF}_{2}$. Nature: New Biology. London, 224, 114.

Weiss, H.J., Danese, C.A. \& Valeti, C.D. (1970) Prevention of experimentally induced arterial thrombosis by aspirin. Federation Proceedings, 29, 381.

Weiss, H.J., Aledort, L.M. \& Kochwa, S. (1968) The effect of salicylates on the haemostatic properties of platelets in man. Journal of Clinical Investigation, 47, 2169.

Woop, L. (1972) Treatment of atherosclerosis and thrombosis with asprin. Lancet, ii 532.

Zucker, M.B. \& Peterson, J. (1968) Inhibition of adenosine diphosphate induced secondary aggregation and other platelet functions by acetyl salicylic acid ingestion. Proceedings of the Society for Experimental Biology and Medicine, 127, 547. 